\title{
Can the Kydland-Prescott Model Pass the Cogley-Nason Test?
}

\author{
Patrick Fève ${ }^{1}$ \\ University of Toulouse (CNRS-GREMAQ and IDEI) \\ and Banque de France (Research Division) \\ Julien Matheron \\ Banque de France (Research Division)
}

April, 2005

${ }^{1}$ Address: GREMAQ-Université de Toulouse I, manufacture des Tabacs, bât. F, 21 allée de Brienne, 31000 Toulouse, France. email: patrick.feve@univ-tlse1.fr. We would like to thank F. Collard and M. Dupaigne for helpful discussions. The traditional disclaimer applies. The views expressed herein are those of the authors and not necessarily those of the Banque de France. 


\begin{abstract}
This paper quantitatively evaluates the ability of a Kydland and Prescott type model with permanent technology shocks and labor wedges to reproduce output persistence together with persistent impulse response functions of output to permanent and transitory shocks. When calibrated on US labor market features, this model, in which technology shocks account for the bulk of output fluctuations, successfully passes the Cogley and Nason test.
\end{abstract}

Keywords: RBC Models, Habit Leisure, Labor Wedges, Output Persistence

JEL Class.: E32, C52 


\section{Introduction}

Cogley and Nason (1995) (CN hereafter) have shown that standard RBC models as well as models that include real frictions and delays generally fail to reproduce autocorrelation function (ACF) of output growth and impulse response functions (IRFs) of output to permanent and transitory shocks. These findings challenge standard RBC models, as they show that their internal propagation mechanisms are rather weak, and thus suggest to abandon them in favor of models incorporating a host of additional frictions. Indeed, these results have stimulated the development of dynamic stochastic general equilibrium models consistent with these stylized facts: job search (Andolfatto, 1996), factor hoarding (Burnside and Eichenbaum, 1996), external increasing returns and indeterminacy (Benhabib and Wen, 2004, Schmitt-Grohe, 2000), sticky wages (Ambler, Guay and Phaneuf, 2003) among others. All these developments share the same idea that many frictions must be added to the basic model, at the cost of abandoning the simplicity of the original mechanisms.

This paper questions this common idea, and investigates the dynamic properties of a simplified version of the KP model with permanent technology shocks and transitory preference shocks. These latter shocks, labelled labor wedges, account for persistent shifts in the marginal rate of substitution between goods and labor. The model is estimated so as to match US labor market features (notably the negative correlation between labor productivity and hours). Importantly, we obtain that the business cycle fluctuations of output originate mainly from the technology shock. We show that this model with leisure habit can pass the $\mathrm{CN}$ test. This result contradicts the previous findings of $\mathrm{CN}$. The reasons why are simple. First, our estimation emphasizes that the labor supply is complementary across time, while CN focus on specifications in which hours display strong intertemporal substitution. Under the intertemporal substitution hypothesis, hours are weakly serially correlated, thus shutting down the main channel of persistence. ${ }^{1}$ Second, CN consider a technology shock and a government spending shock. This latter shock does not allow to match ACF and IRFs

\footnotetext{
${ }^{1}$ As emphasized by Benhabid and Wen (2004), while physical capital is highly serially correlated in RBC models, changes in output are not, because the elasticity of output to capital is small in standard specifications. This implies that output is persitent insofar as hours are.
} 
of output growth estimated with US data for plausible calibrations. Notice also that an RBC model with government spending and technology shocks experiences troubles reproducing the salient features of US labor market fluctuations, e.g. Christiano and Eichenbaum (1992). To the contrary, the KP model with labor wedges and a powerful internal propagation mechanism (leisure habit) succeeds in reproducing these stylized facts. These two features need to be combined together in order for the model to successfully pass the CN test.

The paper is organized as follows. In a first section, we present our simplified KP model. The second section is devoted to the exposition of the calibration and the parameters estimation. In a third section, we present the results on the CN tests. The last section concludes.

\section{A Kydland-Prescott Type Model}

We consider a simplified version of the KP model with two shocks: a random walk productivity shock $\left(Z_{t}\right)$ and a stationary preference shock $\left(\chi_{t}\right)$. We assume that intertemporal leisure choices are not time separable - as in $\mathrm{KP}-$, and that the service flows from leisure are a linear function of current and once-lagged leisure choices. The representative household maximizes

$$
\mathrm{E}_{t} \sum_{i=0}^{\infty} \beta^{i}\left\{\log \left(C_{t+i}\right)+\bar{\chi} \exp \left(\chi_{t+i}\right) \log \left(\mathcal{L}_{t+i}^{\star}\right)\right\},
$$

where $\bar{\chi}>0, \beta \in(0,1)$ denotes the discount factor and $\mathrm{E}_{t}$ is the expectation operator conditional on the information set available at $t . C_{t}$ is consumption at $t$ and $\mathcal{L}_{t}^{\star}$ is the service flow from leisure $\mathcal{L}_{t}$. The labor supply $N_{t} \equiv 1-\mathcal{L}_{t}$ is subject to a stochastic shock $\chi_{t}$, that follows the process

$$
\chi_{t}=\rho_{\chi} \chi_{t-1}+\sigma_{\chi} \varepsilon_{\chi, t}, \quad\left|\rho_{\chi}\right|<1, \quad \sigma_{\chi}>0
$$

where $\varepsilon_{\chi, t}$ is iid with zero mean and unit variance. As noticed by Galí (2004), this shock can be an important source of fluctuations, as it accounts for shifts in the marginal rate of substitution between goods and labor (see Hall, 1997). Such shifts capture persistent fluctuations in the labor supply following changes in labor market participation and/or 
changes in the demographic structure. Notice that this shock is observationally equivalent to a tax shock on labor income, though it does not necessarily reduce to this interpretation. In particular, this preference shock allows us to account for other distortions on the labor market, labelled labor wedges in the words of Chari, Kehoe and McGrattan (2004a). ${ }^{2}$ The service flow of leisure is assumed to evolve according to the law of motion $\mathcal{L}_{t}^{\star}=\mathcal{L}_{t}-b \mathcal{L}_{t-1}$. Though simpler, this form of the utility function is similar to that considered by KP. The main difference with KP is the sign of $b$. KP require that $b$ be strictly negative, implying that current and future leisure choices are intertemporally substitutable. We do not a priori impose this restriction and let the data select $b$.

The representative firm uses capital $K_{t}$ and labor $N_{t}$ to produce the homogeneous final good $Y_{t}$. The technology is represented by the following constant returns-to-scale Cobb-Douglas production function

$$
Y_{t}=K_{t}^{1-\alpha}\left(Z_{t} N_{t}\right)^{\alpha}
$$

where $\alpha \in(0,1)$. $Z_{t}$ is assumed to follow an exogenous process of the form

$$
\log \left(Z_{t}\right)=\gamma_{z}+\log \left(Z_{t-1}\right)+\sigma_{z} \varepsilon_{z, t}, \quad \sigma_{z}>0
$$

where $\varepsilon_{z, t}$ is iid with zero mean and unit variance. The constant $\gamma_{z}$ is a drift term in the random walk process of $Z_{t}$. The capital stock evolves according to the law of motion $K_{t+1}=(1-\delta) K_{t}+I_{t}$, where $\delta \in(0,1)$ is the constant depreciation rate. Finally, the final good can be either consumed or invested, $Y_{t}=C_{t}+I_{t}$.

We first apply a stationary-inducing transformation for variables that follow a stochastic trend. Output, consumption and investment are divided by $Z_{t}$, and the capital stock is divided by $Z_{t-1}$. The approximate solution of the model is computed from a log-linearization of the stationary equilibrium conditions around the deterministic steady state.

\footnotetext{
${ }^{2}$ For example, they show that a sticky-wage economy or a real economy with unions will map it into a simple model economy with this type of shock.
} 


\section{Calibration}

Let $\boldsymbol{\theta}$ denote the model parameters. We partition $\boldsymbol{\theta}$ into two groups $\boldsymbol{\theta}=\left\{\boldsymbol{\theta}_{1}, \boldsymbol{\theta}_{2}\right\}$.

The first group, denoted $\boldsymbol{\theta}_{1}$, is composed of $\bar{\chi}, \gamma_{z}, \beta, \alpha$, and $\delta$, which are calibrated prior to estimation (see Table 1 ). The parameter $\bar{\chi}$ is pinned down so that the steady state labor supply amounts to one third of the time endowment. The quarterly growth rate of $Z_{t}$, $\gamma_{z}$, is equal to 0.0036 . We set $\beta=1.03^{-0.25}$, which implies a steady state annualized real interest rate of $3 \%$. We pin down $\alpha$ so that the steady state capital's share in output is $40 \%$ $(\alpha=0.60)$. Finally, we select $\delta=0.025$, which implies an annual rate of depreciation of capital equal to $10 \%$.

The second group of model parameters is $\boldsymbol{\theta}_{2}=\left\{b, \rho_{\chi}, \sigma_{\chi}, \sigma_{z}\right\}$. These four parameters are estimated using a method of moments on HP-filtered US data for the period 1954:1-2002:4. Output is measured as real GDP divided by civilian population over 16. Hours are defined as per capita non-farm business hours worked. Finally, labor productivity is measured as real GDP divided by hours. All measures are in logs. The four moments selected for estimation are the standard-error of output $\left(\sigma_{y}=0.016\right)$, the standard-error of hours over that of output $\left(\sigma_{n} / \sigma_{y}=1.123\right)$, the first order serial correlation of hours $\left(\rho_{n}=0.904\right)$, and the correlation between labor productivity and hours $(\operatorname{Corr}(y / n, n)=-0.455)$. The estimation results are reported in Table 1 . The model exactly matches the data since the number of parameters to be estimated is equal to the number of selected moments. ${ }^{3}$

The labor supply parameter $b$ is positive and large, indicating that labor supply is subject to strong intertemporal complementarities, as in Eichenbaum, Hansen and Singleton (1988), Bover (1991) and Wen (1998). The estimated value of the standard-error of the technology shock $\sigma_{z}$ is comparable to those used in previous studies (Hansen, 1997, Erceg, Guerrieri and Gust, 2004). The estimated value of the autoregressive parameter $\rho_{\chi}$ is rather large, yet close to previous estimates. For example, Chari, Kehoe and McGrattan (2004b) report estimated values between 0.94 and 0.97 . Finally, the estimated value of $\sigma_{\chi}$ is similar to what Erceg, Guerrieri and Gust (2004) and Chari, Kehoe and McGrattan (2004b) obtain.

\footnotetext{
${ }^{3}$ Notice that standard RBC models usually fail to replicate these moments.
} 
Table 1 also reports the variance decomposition for the business cycle components of output and hours after HP filtering the series simulated from the estimated RBC model. The fraction of the variance of hours at business cycle frequencies explained by the technology shock $\mathrm{V}\left(n / \varepsilon_{z}\right)$ is rather small $(15 \%)$, thus suggesting that labor wedges account for most of labor market fluctuations. In contrast, technology shocks account for the bulk of output fluctuations (more than 70\%), as argued by Prescott (1986). In the remainder, we thus assess and test the ability of the model to reproduce the dynamics of output, keeping in mind that technology shocks are the main driving force of output fluctuations.

\section{Output Dynamics}

Using the above calibration, we now assess the ability of this simple model to pass the CN test, using the exact same methodology as theirs. We generate artificial data by simulating the model and we compute ACF of output growth and IRFs of output to permanent and transitory shocks. We then compare the population of these numbers (ACF and IRFs) to estimated values with actual data and we test their equality using the following $\mathbf{Q}$ statistic:

$$
\mathrm{Q}_{\mathrm{i}}=\left(\widehat{\mathbf{r}}_{\mathrm{i}}-\mathbf{r}_{\mathrm{i}}\right)^{\prime} \mathbf{V}_{\mathbf{r}, \mathrm{i}}{ }^{-1}\left(\widehat{\mathbf{r}}_{\mathrm{i}}-\mathbf{r}_{\mathrm{i}}\right) \quad \mathrm{i}=\{\operatorname{acf}, \operatorname{irf}\}
$$

where $\mathbf{r}_{\mathrm{i}}$ is the sample autocorrelation function $(\mathrm{i}=\mathrm{acf})$ of output growth or impulse response functions $(\mathrm{i}=\operatorname{irf})$ of output to a permanent shock or a transitory shock. $\widehat{\mathbf{r}}_{\mathrm{i}}$ denotes the sample estimate and $\mathbf{r}_{\mathrm{i}}=(1 / S) \sum_{s=1}^{S} \mathbf{r}_{s, \mathrm{i}}$ is the average over $S=100$ simulations from the model. The covariance matrix $\mathbf{V}_{\mathbf{r}, \mathrm{i}}$ is:

$$
\mathbf{V}_{\mathbf{r}, \mathrm{i}}=\frac{1}{S} \sum_{s=1}^{S}\left(\mathbf{r}_{\mathbf{s}}-\mathbf{r}\right)\left(\mathbf{r}_{\mathbf{s}}-\mathbf{r}\right)^{\prime}
$$

The ACF are obtained directly from the auto-covariance functions of per capita US output growth. In order to estimate the impulse response functions, we use the Structural VAR approach developed by Blanchard and Quah (1989). We first estimate a VAR model of output growth $\Delta y_{t}$ and hours $n_{t}$ with two lags, over the period 1954:1-2002:4. The number 
of lags is selected according to the Hannan-Quinn criterion. The IRFs are thus computed using long run restrictions, i.e. innovations to hours worked have no long run effect on the level of output. ${ }^{4}$ The same SVAR model is used in order to compute IRFs from artificial data. We follow $\mathrm{CN}$ and select height lags both for ACF and IRFs. Consequently each $\mathbf{Q}_{\mathrm{i}}$ statistic follows a chi-square with eight degrees of freedom.

Figure 1 reports the ACF of output growth from actual and artificial data. This Figure shows that the model reproduces well the observed persistence of output growth in the short run. The $\mathbf{Q}_{\text {acf }}$ statistic indicates that the model is not rejected at conventional levels (see Table 2). This result is not surprizing as Wen (1998) has already shown that a model with leisure habit possesses strong internal persistence mechanisms.

Figure 2 reports the IRFs of output to a permanent shock $\left(y_{P}\right)$ and to a transitory shock $\left(y_{T}\right)$. The model has a tendency to over-estimate the response to a permanent shock and to under-estimate the response to a transitory shock. However, both the $\mathbf{Q}_{\mathrm{irf}}-y_{P}$ and the $\mathbf{Q}_{\text {irf }}-y_{T}$ statistics indicate that the two IRFs do not significantly differ (see Table 2). Thus, a streamlined version of the KP model with labor wedges easily passes the CN test.

This result is in sharp contrast with those of $\mathrm{CN}$, who have shown that none of the RBC models (including the KP model or model with labor adjustment costs) can produce ACF or IRFs consistent with the data. First, they have shown that the KP model fails to match the observed ACF, but our results indicates that this need not be the case. The difference in the result can be simply explained by the difference in the calibration of the habit parameter $b$. In KP, this parameter is set to be negative, implying a strong intertemporal substitution in leisure but a weaker persistence of aggregate variables. Our estimation results suggest a positive value, implying more persistence in hours and output, so that the model is able to match satisfactorily the data. When we set $b=0$, the $\mathbf{Q}_{\mathbf{i}}$ statistics takes on very large values and the model can reproduce neither the ACF nor the IRFs (see Table 2). Second, $\mathrm{CN}$ have shown that RBC models with employment lags or labor adjustment costs succeed at reproducing ACF, but fail to match IRFs. Our results contradict their findings. Again,

\footnotetext{
${ }^{4} \mathrm{~A}$ notable feature of these IRFs is the hump-shape and persistent pattern of the response of output to a non technology shock. See Figure 2.
} 
this difference can easily be explained. In CN, the transitory shock is a government spending shock in deviation from the stochastic trend. The calibration they use allows them to match the variance of per capita GNP growth, but fails to properly account for labor market features, i.e. the negative correlation between the cyclical components of labor productivity and hours (see Christiano and Eichenbaum (1992), Table 4, p. 444). In contrast, the labor wedges shock in the KP type model does this job, together with persistence in hours provided by leisure habit.

To confirm this insight, Table 2 reports two complementary experiments. In the first one, we shut down the autocorrelation of $\chi_{t}$. Neither ACF nor IRFs are properly reproduced under this restriction. Notice that in this case, the $\mathbf{Q}_{\text {irf }}-y_{T}$ statistic is in line with results reported by $\mathrm{CN}$ : the most patent failure of $\mathrm{RBC}$ models is their inability to reproduce the hump-shaped response to a transitory shock. In the second experiment, we set $\sigma_{\chi}$ to a hundredth of its estimated value. The model is unable to match the IRFs under actual data. Yet, it delivers slightly more encouraging results when it comes to ACF, that can easily be explained by the strong intertemporal complementarity of the labor supply.

\section{Concluding Remarks}

In this paper, we have shown that a simplified version of the KP model with a technology shock and labor wedges is able to replicate the observed persistence in output. More precisely, our results shows that when estimated on labor market features, leisure habit and labor supply shocks account for the persistence of output growth and the hump-shaped response of output to a transitory shock. 


\section{References}

Ambler S., Guay A. and L. Phaneuf (2003) "Labor Market Imperfections and the Dynamics of Postwar Business Cycles", mimeo CIRPEE-UQAM.

Andolfatto D. (1996) "Business Cycles and Labor-Market Search", American Economic Review, 86(1), pp. 112-132

Benhabib J., Wen Y. (2004) "Indeterminacy, Aggregate Demand and the Real Business Cycle", Journal of Monetary Economics, 51, pp. 503-530.

Blanchard, O.J. and D. Quah (1989) "The Dynamic Effects of Aggregate Demand and Supply Disturbances" , American Economic Review, 79(4), pp. 655-673.

Bover, O. (1991) "Relaxing intertemporal separability: a Rational Habit Model of Labor Supply Estimated from Panel Data", Journal of Labor Economics, 9, pp. 85-100.

Burnside, C. and M. Eichenbaum (1996) "Factor hoarding and the propagation of business cycle shocks", American Economic Review, 86, pp. 1154-1174.

Chari, V., Kehoe, P. and E. Mc Grattan (2004a) "Business Cycle Accounting", Federal Reserve Bank of Minneapolis, Research Department, Staff Report 328.

Chari, V., Kehoe, P. and E. McGrattan (2004b) "A Critique of Structural VARs Using Real Business Cycle Theory", Federal Reserve Bank of Minneapolis, Research Department, Working Paper 631.

Christiano L. and M. Eichenbaum (1992) "'Current Real Business Cycle Theories and Aggregate Labor Market Fluctuations", American Economic Review, 82(3), pp. 430-450.

Cogley, T. and J. Nason (1995) "Output Dynamics in Real Business-Cycle Models", American Economic Review, 85-3), pp. 495-511. 
Eichenbaum M., Hansen L. and K. Singleton (1988) "A Time Series Analysis of Representative Agent Models of Consumption and Leisure Choice under Uncertainty", Quarterly Journal of Economics, 103(1), pp. 51-78.

Erceg, C., Guerrieri, L. and C. Gust (2004) "Can Long-Run Restrictions Identify Technology Shocks", Board of Governors of the Federal Reserve System, International Finance Discussion paper, Number 792.

Galí, J. (2004) "Trends in Hours Worked and the Role of Technology in the Business Cycle Theory: Theory and International Evidence", prepared for the 29th Economic Policy Conference on Productivity, Labor and the Business Cycle, Federal Reserve Bank of St. Louis, October 20-21, 2004.

Hall, R. (1997) "Macroeconomic Fluctuations and the Allocation of Time", Journal of Labor Economics, 15(1), pp. 223-250.

Hansen, G. (1997). "Technical Progress and Aggregate Fluctuations", Journal of Economic Dynamics and Control, 21, pp.1005-1023.

Kydland, F. and E. Prescott (1982) "Time-to-Build and Aggregate Fluctuations", Econometrica, 50(6), pp. 1345-1370.

Prescott, E., (1986). "Theory Ahead of Business Cycle Measurement", Quarterly Review, 10, pp. 9-22, Federal Reserve Bank of Minneapolis.

Schmitt-Grohé S. (2000) "Endogenous Business Cycles and the Dynamics of Output, Hours and Consumption", American Economic Review, 90(5), pp. 1136-1159.

Wen, Y. (1998) "Can a Real Business Cycle Model Pass the Watson Test?", Journal of Monetary Economics, 42, pp. 185-203. 
Table 1: Estimation Results

\begin{tabular}{cccc}
\hline \hline Parameters & Calibrated Value $\boldsymbol{\theta}_{1}$ & Parameters & Estimated Value $\boldsymbol{\theta}_{2}$ \\
\hline$\beta$ & 0.9926 & $b$ & 0.7254 \\
$\alpha$ & 0.6000 & $\rho_{\chi}$ & 0.9313 \\
$\delta$ & 0.0250 & $\sigma_{\chi}$ & 0.0187 \\
$\gamma_{z}$ & 0.0036 & $\sigma_{z}$ & 0.0136 \\
\hline $\mathrm{V}\left(y / \varepsilon_{z}\right)$ & $73.9 \%$ & & \\
$\mathrm{~V}\left(n / \varepsilon_{z}\right)$ & $14.9 \%$ & \\
\hline \hline
\end{tabular}


Table 2: The Cogley and Nason Test

\begin{tabular}{cccc}
\hline \hline & \multirow{2}{c}{$\mathbf{Q}_{\text {acf }}$} & \multicolumn{2}{c}{$\mathbf{Q}_{\text {irf }}$} \\
\cline { 3 - 4 } & & $y_{P}$ & $y_{T}$ \\
& & & \\
Benchmark & 6.33 & 14.24 & 3.21 \\
& $(60.94 \%)$ & $(7.56 \%)$ & $(91.92 \%)$ \\
Case $b=0$ & 27.73 & 22.28 & 106.31 \\
Case $\rho_{\chi}=0$ & $(0.05 \%)$ & $(0.44 \%)$ & $(0.00 \%)$ \\
& 28.12 & 26.68 & 900.04 \\
Case $\sigma_{\chi} / 100$ & $(0.04 \%)$ & $(0.08 \%)$ & $(0.00 \%)$ \\
& & & \\
& & & \\
& & 35.84 & 1233.20 \\
\hline \hline
\end{tabular}


Figure 1: ACF of output growth

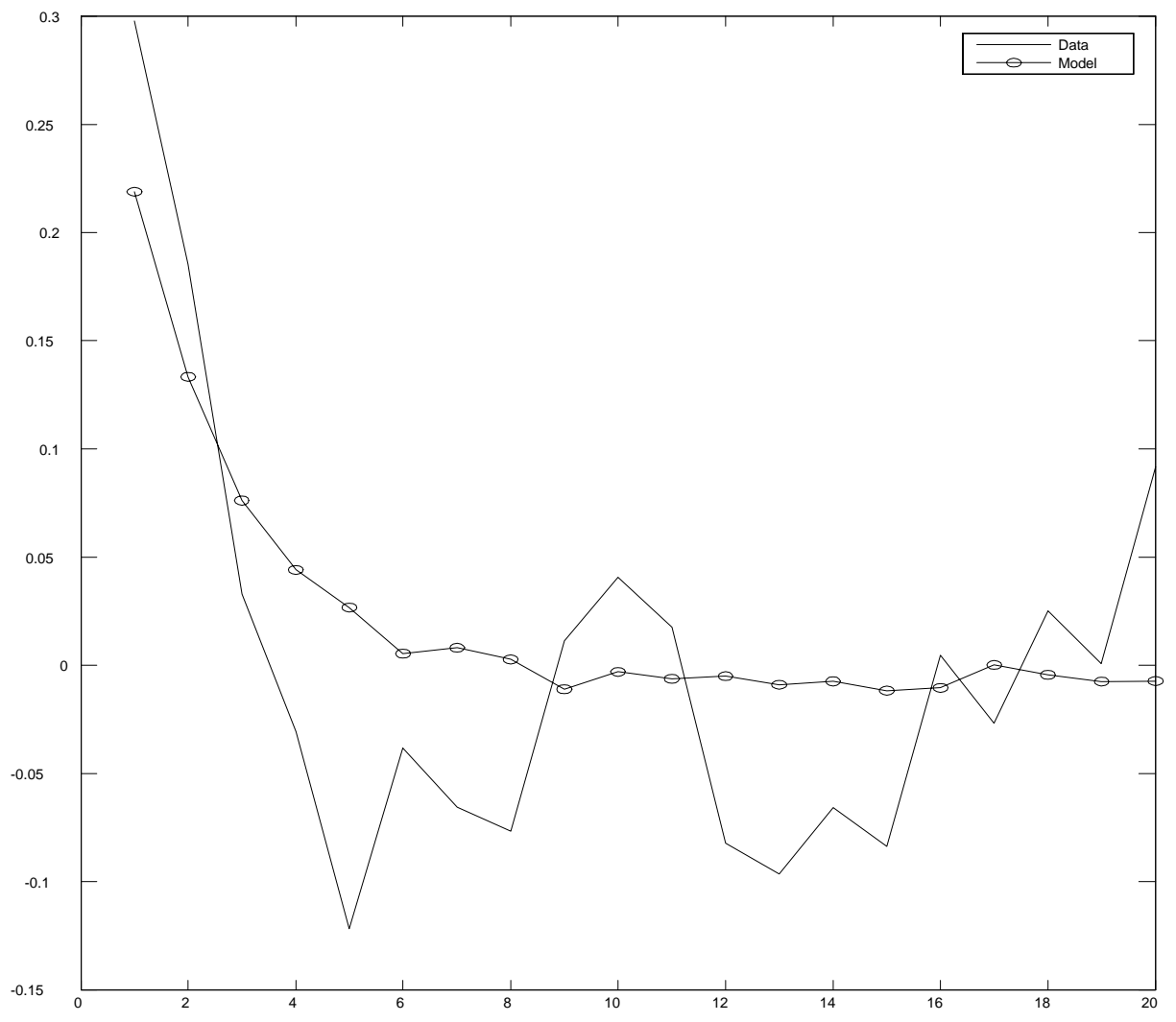


Figure 2: IRFs of output growth

Tech. Shock
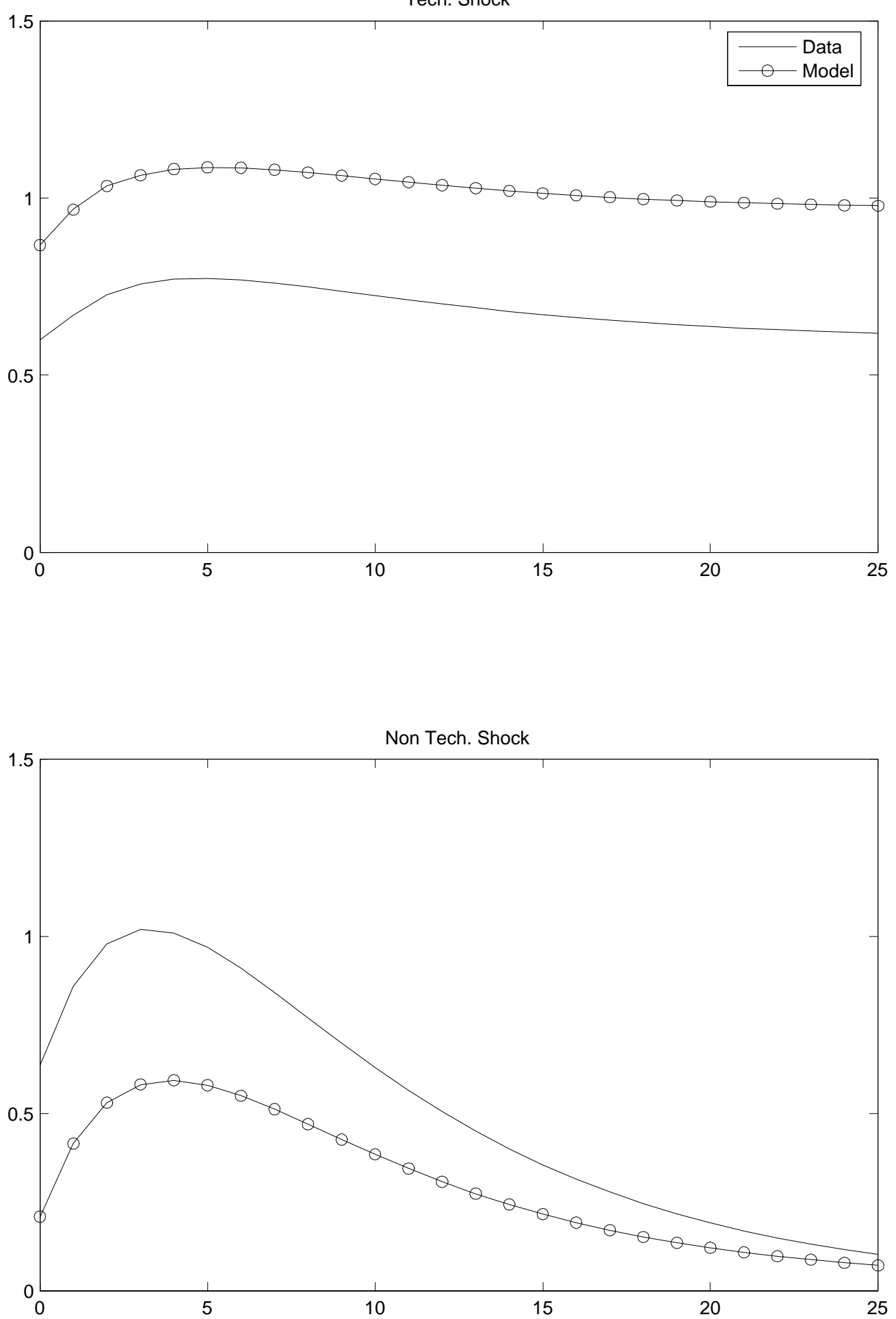